\title{
Cerebral Artery Hypoplasia in a Select Adult Kenyan Population
}

\author{
Julius A. Ogengo ${ }^{1}$ Isaac Cheruiyot ${ }^{1}$ Thomas Amuti ${ }^{1} \quad$ Ibsen Ongidi ${ }^{1}$ Philip Mwachaka ${ }^{1}$
}

Beda Olabu' ${ }^{1}$ Peter Kitunguu ${ }^{1}$ Simeon Sinkeet ${ }^{1}$

${ }^{1}$ Department of Human Anatomy, University of Nairobi, Nairobi,

Address for correspondence Thomas Amuti, BSc, Department of Human Anatomy, University of Nairobi, P.O. Box 00100, 30197, Nairobi, Kenya (e-mail: tomamuti@gmail.com).

J Neurosci Rural Pract 2019;10:423-429

\begin{abstract}
Background Hypoplasia of cerebral arteries predisposes to stroke and cerebral aneurysms which have an increased incidence in sub-Saharan Africa. The frequency and pattern of cerebral artery hypoplasia, however, shows population variations, and data from the African population remain scanty.

Objectives This study aimed to determine the percentage of hypoplasia in the anterior, middle, and posterior cerebral, anterior and posterior communicating, basilar, and vertebral arteries.

Materials and Methods Sections of the basilar, vertebral, posterior, and anterior communicating arteries and anterior, middle, and posterior cerebral arteries were taken, processed for histology, and examined with a light microscope at $\times 40$. The images of the vessels were taken by a photomicroscope and circumference analyzed with the aid of Scion image analyzer. The average diameter of 10 sections was taken to be the diameter of the artery in analysis. Hypoplasia was then defined as internal diameter $\leq 1 \mathrm{~mm}$. Photographs of representative samples of asymmetry were taken, data were analyzed using SPSS, and gender differences were analyzed using the Student's test. Results were presented in tables.

Results Two hundred and eighteen formalin-fixed brains of adult Kenyans at the Department of Human Anatomy, University of Nairobi, were studied. Of the 218, 48

Keywords

- anterior

- cerebral artery

- hypoplasia

- posterior brains (22\%) did not have vessels with any form of hypoplasia while 170 (78\%) did have vessels. Of these, anterior circulation hypoplasia (anterior cerebral artery and posterior communicating artery) was seen in 100 brains (46\%) and posterior circulation hypoplasia (middle and posterior cerebral, basilar, and vertebral arteries) in 69 brains (32\%). Conclusion Cerebral arterial hypoplasia is frequent in the select adult Kenyan population.
\end{abstract}

\section{Introduction}

Hypoplasia in cerebral arteries has been shown to alter hemodynamics in the affected arteries as well as the normal arteries in the same vascular bed..$^{1,2}$ It further influences the pattern of cerebral blood flow ${ }^{3}$ and predisposes to atherosclerosis of large and small cerebral arteries alike, causing stroke and transient ischemic attacks. ${ }^{1,2,4}$ Hypoplasia also causes cerebral aneurysms, ${ }^{5}$ may be associated with deformities of other intracranial arteries, ${ }^{6,7}$ and can be confused for pathological arterial occlusion. ${ }^{8}$ Cerebral hypoplasia has the potential to cause cerebral hypoperfusion and thus predisposes to cognitive dysfunction and Alzheimer's disease. ${ }^{9}$ Knowledge on cerebral hypoplasia is important during instrumentation of arteries as well as mitigating complications of endovascular treatment and prognostication of cerebrovascular 
disease. ${ }^{6}$ Further, it is also important to surgeons in planning shunt operations, choice of patients, and avoidance of inadvertent vascular trauma during surgery. ${ }^{10}$

Stroke, cerebrovascular disease, and cognitive decline are now recognized to be leading causes of mortality and morbidity in sub-Saharan Africa, including in Kenya. ${ }^{11}$ Since these conditions are predisposed by cerebral artery hypoplasia, and in an attempt to link their possible causation to cerebral artery hypoplasia, a study on the same in the Kenyan setting is paramount.

Hypoplasia of cerebral arteries has been shown to display ethnic variation, ${ }^{12}$ and data from the African populations are scarce. The prevalence of hypoplasia from our findings might help to explain the high prevalence of cerebrovascular disease, stroke, and cognitive impairment. ${ }^{13,14}$

This study, therefore, aimed to determine the prevalence of cerebral artery hypoplasia of several cerebral arteries in a select adult Kenyan population.

\section{Materials and Methods}

The study was done on 218 formalin-fixed brains from adult adult Kenyans (124 males; 94 females, age range: 20-79 years) obtained during autopsy at the Department of Human Anatomy, University of Nairobi, Kenya. Ethical approval was granted by the Kenyatta National Hospital/ University of Nairobi Ethics and Research Committee and the Kenyan constitution. Further, consent was sought from each family member, and benefits of the study were explicitly explained to them before any dissections.

Cases of suspected cerebrovascular disease influenced by other cardiovascular risk factors and damaged arteries were excluded to minimize the potential confounding effect of these pathological conditions (such as atherosclerotic arterial narrowing). The cardiovascular risk factors excluded were alcohol (32.3\%), diabetes mellitus (23.4\%), cigarette smoking (20.8\%), and obesity (14.5\%). The study, however, included brains from causes of death such as trauma (60.1\%), infections (21.4\%), malignancy (13.3\%), poisoning (3.5\%), and drowning (1.7\%). The age distribution of the cases is as shown in - Table $\mathbf{1}$. The brains were divided into those of males and females.

Table 1 Age distribution of the population from which the cerebral arteries were obtained

\begin{tabular}{|l|l|l|l|}
\hline \multirow{2}{*}{$\begin{array}{l}\text { Age range } \\
(y)\end{array}$} & \multicolumn{2}{|c|}{ Frequency } & \multirow{2}{*}{ Total (\%) } \\
\cline { 2 - 3 } & Male & Female & \\
\hline $21-30$ & 19 & 15 & $34(15.6)$ \\
\hline $31-40$ & 24 & 19 & $43(19.7)$ \\
\hline $41-50$ & 30 & 23 & $53(24.3)$ \\
\hline $51-60$ & 29 & 22 & $51(23.4)$ \\
\hline $61-70$ & 14 & 10 & $24(11)$ \\
\hline $71-80$ & 8 & 5 & $13(6)$ \\
\hline Total & 124 & 94 & $218(100)$ \\
\hline
\end{tabular}

Arachnoid mater was gently peeled from the base of the brain to expose the basilar, vertebral, posterior, middle, and anterior cerebral arteries and the posterior and anterior communicating arteries. Two-millimeter specimens taken from each of the arteries were then fixed in 10\% formalin and processed for paraffin embedding and sectioning. Ten $5-\mu \mathrm{m}$ serial sections from each arterial site were stained with hematoxylin/eosin and examined with the help of a Leica DM3000 light microscope at $\times 40$. The images taken by the photomicroscope were digitized. Subsequently, the internal circumference of each of the 10 sections from each site of the artery was determined using Scion image analyzer version 1.46. To do this, the image was first set to scale; then, with the help of the line tool, a line was drawn round the lumen of the artery to give a value equivalent to the circumference. Only complete sections were included. The diameter (in millimeters) was calculated from the formula $D=C / \pi$, where $D$ is the diameter, $C$ is the circumference, and $\pi=3.14$. The average diameter of the 10 sections was taken to be the diameter of that artery.

Artery hypoplasia was defined as internal diameter $\leq 1 \mathrm{~mm}$. Photographs of representative samples of asymmetry were taken using a high-resolution digital camera. Data were analyzed using Statistical Package for the Social Science (SPSS; IBM, New York, United States) for Windows. Gender differences were analyzed using the Student's test at $95 \%$ confidence intervals where value of $\leq 0.05$ was taken as significant. Results were presented in tables.

\section{Results}

Of the 218 dissected brain specimens, 170 presented with hypoplasia. The remaining 48 did not exhibit hypoplasia. Of the 170 , anterior cerebral artery hypoplasia was recorded in 13 (6\%) brains with 87 (40\%) showing posterior communicating artery (PCoA) hypoplasia, $26(12 \%)$ showing posterior cerebral artery hypoplasia, 6 (3\%) showing basilar artery hypoplasia, and 37 (17\%) showing vertebral artery hypoplasia (VAH). All the arteries studied, except middle cerebral, displayed hypoplasia. The findings have been summarized ( - Tables 2 and $\mathbf{3}$ and - Fig. 1-5).

\section{Discussion}

Data from our study revealed that of all the arteries studied, the middle cerebral artery did not exhibit hypoplasia.

Table 2 Frequency of hypoplasia of cerebral arteries in adult Kenyans

\begin{tabular}{|l|l|}
\hline Artery & Frequency of hypoplasia (\%) \\
\hline Anterior cerebral & $13(6)$ \\
\hline Posterior communicating & $87(40)$ \\
\hline Posterior cerebral & $26(12)$ \\
\hline Vertebral & $37(17)$ \\
\hline Basilar & $6(3)$ \\
\hline Total & $170(78)$ \\
\hline
\end{tabular}


This finding is similar to prevailing literature from other populations. $^{12}$

Cerebral artery hypoplasia was more common in the anterior circulation (46\%). This is consistent with contemporary literature reports. ${ }^{3,15}$ The mechanisms by which cerebral artery hypoplasia occurs are considered to be related to hemodynamic factors. In this case, the differential growth of

Table 3 Frequency of hypoplasia of the different cerebral arteries in adult Kenyans

\begin{tabular}{|l|l|}
\hline Vascular region & Percentages \\
\hline Anterior circulation & \\
\hline Unilateral right A1 segment & 3 \\
\hline Unilateral left A1 segment & 2 \\
\hline Unilateral A2 segment & 1 \\
\hline Posterior circulation & \\
\hline PCoA & \\
\hline Bilateral & 23 \\
\hline Unilateral left & 13 \\
\hline Unilateral right & 4 \\
\hline PCA & \\
\hline Bilateral & 6 \\
\hline Unilateral left & 2 \\
\hline Unilateral right & 4 \\
\hline VA & \\
\hline Right & 10 \\
\hline Left & 7 \\
\hline BA & 3 \\
\hline
\end{tabular}

Abbreviations: BA, basilar artery; PCA, posterior cerebral artery; PCoA, posterior communicating artery; $\mathrm{VA}$, vertebral artery. the various parts of the brain will continuously change the hemodynamic demands and consequently the flow patterns in the cerebral arteries. ${ }^{16}$ It is, therefore, conceivable that if a selected part of the brain does not develop, the change in the hemodynamic demand in that area will be reduced as noted by Van Overbeeke et al. ${ }^{17}$ The frequency of anterior circulation (anterior cerebral artery and $\mathrm{PCOA}$ ) hypoplasia varied between arteries.

The frequency of A1 hypoplasia is reported to range between 1 and $15 \%{ }^{18-20}$ The A1 segment is the principal supplier of collateral blood flow and origin to striate arteries, which supply the hypothalamus, septum pellucidum, and corpus striatum. Hypoperfusion may, therefore, affect functioning in these areas. Further, in patients with hypoplastic A1 segments, total cerebral blood flow within the ipsilateral internal carotid is usually lower than in the contralateral internal carotid artery (ICA). ${ }^{14}$ This may cause global cerebral hypoperfusion. Accordingly, A1 hypoplasia is a risk factor for stroke-related vascular diseases, ${ }^{19,21}$ has been implicated in mild cognitive impairment, ${ }^{22,23}$ and may present with monoplegia, abulia, and urinary incontinence. It is also a risk factor for the occurrence of anterior communicating artery (ACoA) aneurysms. ${ }^{24}$ In the current study, A1 hypoplasia occurred in $6 \%$, which was notably higher when compared with the Polish (3\%), ${ }^{25}$ the Indians (4\%), ${ }^{10}$ and the Sri Lankans (5\%) (-Table 4). It was, however, lower when compared with the Taiwanese (15\%). ${ }^{19}$ The relatively higher prevalence observed among Kenyans as compared with many of the other populations may explain the high prevalence of aneurysms of ACoA. ${ }^{11,27}$ Pertinent to this suggestion is the observation that A1 hypoplasia predisposes to ACoA aneurysm. ${ }^{5}$

Posterior cerebral artery was hypoplastic in $12 \%$ of the cases. This was higher than that recorded in the Ameri$\operatorname{can}^{28}(6.3 \%)$, Indian ${ }^{29}(5.29 \%)$, Polish $^{12}(4 \%)$, and Pakistani ${ }^{30}$ (0\%) populations (-Table 5). It was notably lower when

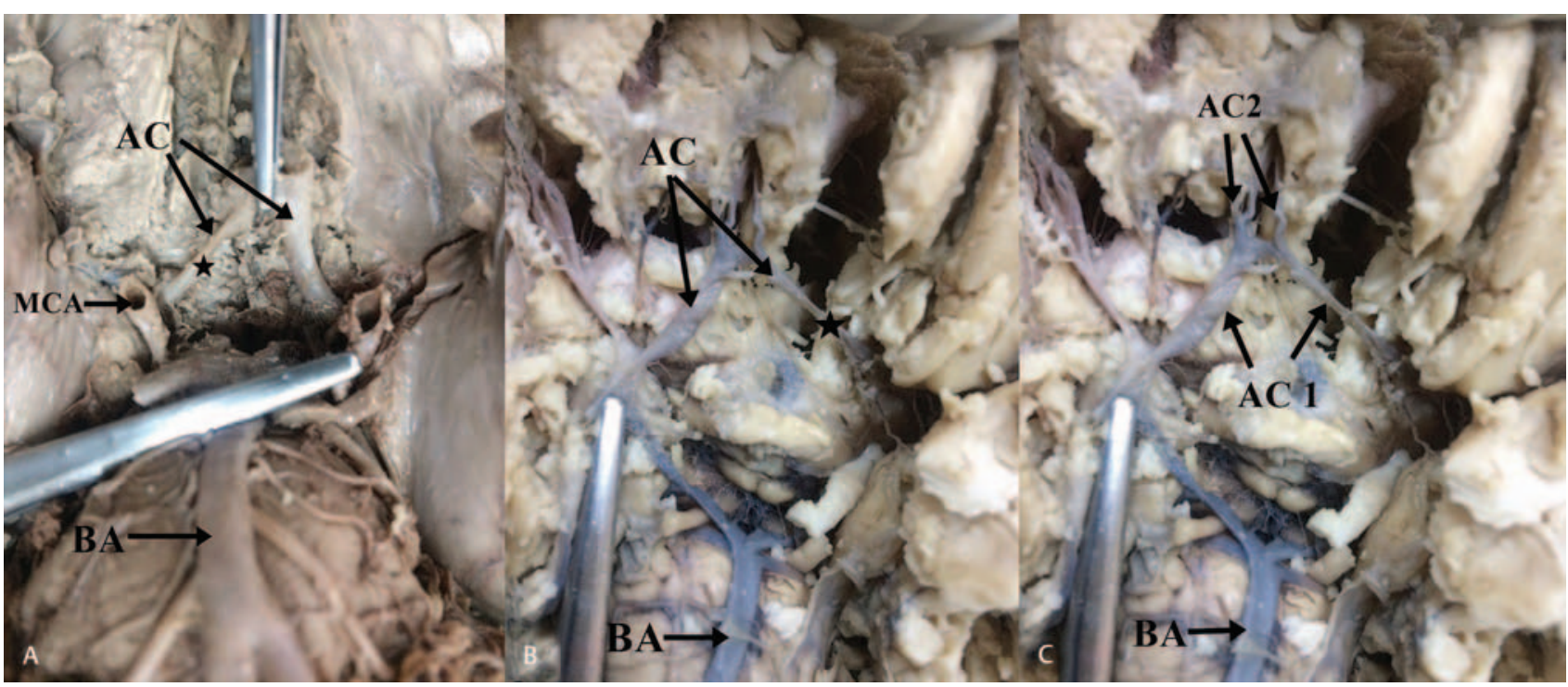

Fig. 1 (A) Unilateral hypoplasia of A1 segment of the left anterior cerebral artery. Note the asterisk which highlights the variant artery. (B) Unilateral hypoplasia of A1 segment right anterior cerebral artery. Note the asterisk which highlights the variant segment. (C) Unilateral hypoplasia of A2 segment of anterior cerebral artery 2. Abbreviations: AC 1, first part of anterior cerebral; BA, basilar artery; MCA, middle cerebral artery. 


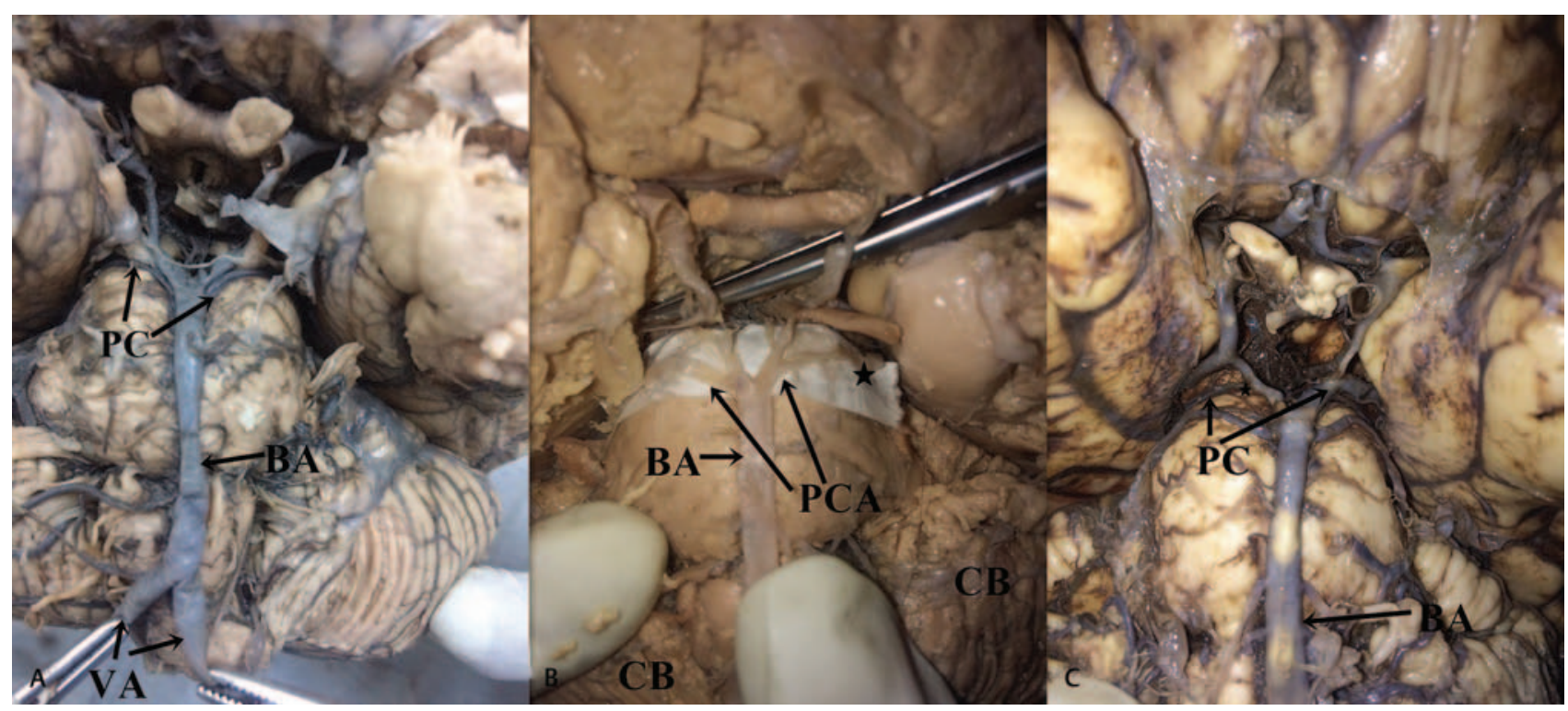

Fig. 2 (A) Bilateral hypoplasia of posterior cerebral artery (note the asterisk). (B) Unilateral hypoplasia of the right posterior cerebral artery. (C) Unilateral hypoplasia of the left posterior cerebral artery. Abbreviations: BA, basilar artery; CB, cerebellum.

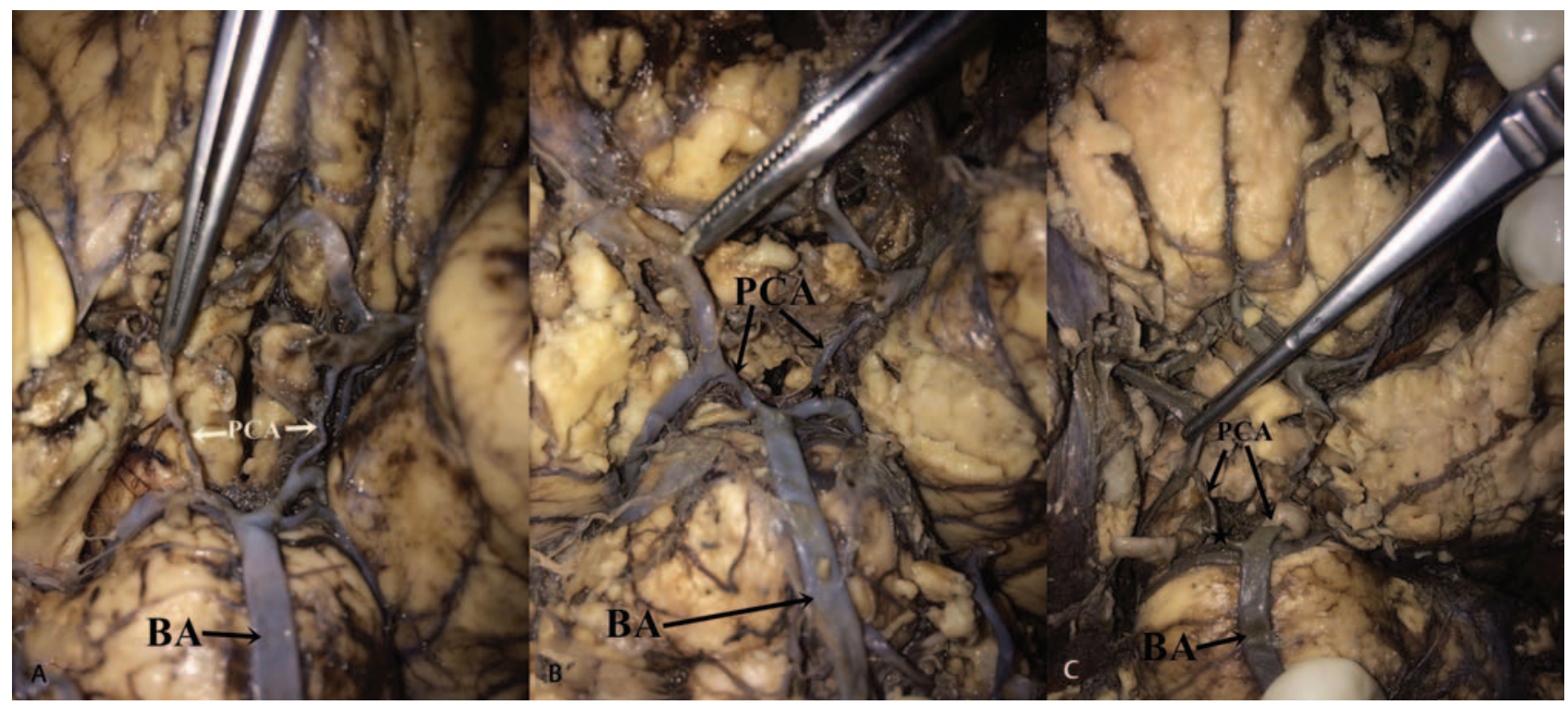

Fig. 3 (A) Bilateral hypoplasia of posterior communicating artery. (B) Unilateral hypoplasia of the right posterior communicating artery. (C) Unilateral hypoplasia of the left posterior communicating artery. Abbreviation: BA, basilar artery.

compared with the German ${ }^{31}$ (37.5\%) population and other populations. ${ }^{32,33}$ The higher prevalence in the Kenyan setting as compared with most of the other populations may predispose to bilateral paramedian thalamic strokes and ischemic strokes, which have been reported to be high in Africa.

The $40 \%$ incidence of PCoA hypoplasia observed in the current study is lower to the $51 \%$ reported for the Sri Lankan population. ${ }^{26}$ It is, however, much higher than that noted in Korean (19.35\%), Dutch (28\%), Indian (23.3\%), and Polish (24\%) populations ${ }^{34-39}$ and previous study on the Kenyan population (-Table 6). The high variability even among ethnically related Caucasian populations suggests that epigenetic factors are involved in the causation of this variation.
Hypoplasia of PCoA increases the risk of atherosclerosis of large and small intracranial arteries and hence ischemic posterior circulatory strokes. ${ }^{1,34}$

Basilar artery hypoplasia has been reported to be a rare occurrence frequently linked to persistent carotid-basilar communication or correlated with the presence of a large PCoA with persistent flow from the carotid to vertebrobasilar system. Cases of these variations are scarce in the literature with a case study being reported in the Italian population ${ }^{40}$ and 1 case of 62 specimens being noted in the Spanish population..$^{32}$ In our setting, the basilar artery was hypoplastic in $3 \%$ of the sample population. Basilar artery hypoplasia has been shown to occur following persistent axial nonfusion of the distal basilar artery, which develops 
from the caudal division of the ICA to the posterior inferior cerebellar artery termination of the vertebral artery. ${ }^{40}$ Basilar artery hypoplasia has been linked to chronic brain hypoperfusion and a subsequent posterior circulation insufficiency. ${ }^{40}$

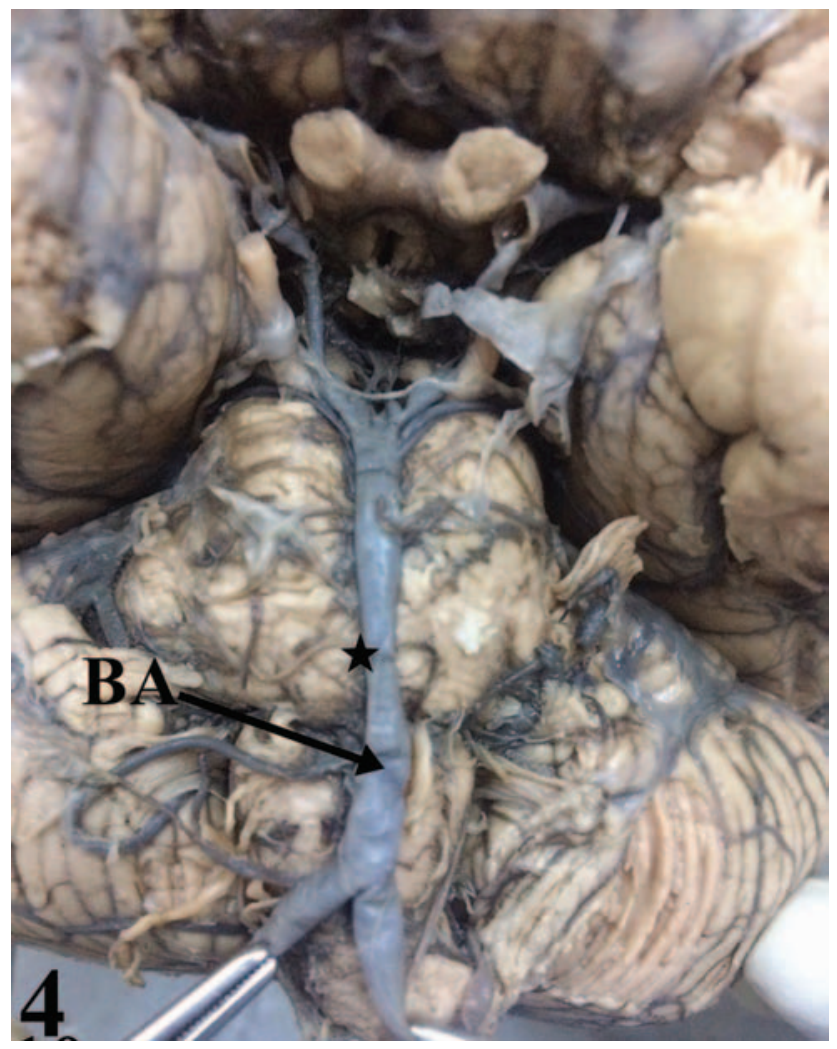

Fig. 4 Basilar artery hypoplasia.

Table 4 Frequency of hypoplasia on anterior cerebral artery in different populations

\begin{tabular}{|l|l|l|}
\hline Reference & Population & Frequency (\%) \\
\hline $\begin{array}{l}\text { Chuang et al, } \\
2007^{19}\end{array}$ & Taiwanese & 15 \\
\hline $\begin{array}{l}\text { De Silva et al, } \\
2009^{26}\end{array}$ & Sri Lankan & 5 \\
\hline $\begin{array}{l}\text { Klimek- } \\
\text { Piotrowska et al, } \\
2016^{12}\end{array}$ & Polish & 1.0 \\
\hline $\begin{array}{l}\text { Makowicz et al, } \\
2013^{25}\end{array}$ & Polish & 3 \\
\hline lqbal, 2013 10 & Indian & 4 \\
\hline Current study & Kenyan & 6 \\
\hline
\end{tabular}

Table 5 Frequency of hypoplasia of posterior cerebral artery in various populations

\begin{tabular}{|l|l|l|}
\hline Reference & Population & Frequency \\
\hline Förster et al, 2014 & German & 37.5 \\
\hline Alpers et al, $1959^{30}$ & American & 6.3 \\
\hline Gunnal et al, 2015 & Indian & 5.29 \\
\hline $\begin{array}{l}\text { Klimek-Piotrowska et al, } \\
2016^{12}\end{array}$ & Polish & 4 \\
\hline Siddiqi et al, 2013 & & \\
\hline $\begin{array}{l}\text { Puchades-Orts et al, } \\
1976^{32}\end{array}$ & Pakistani & 0 \\
\hline Milenković et al, 198533 & & 11.3 \\
\hline Iqbal, 2013 & & 7.68 \\
\hline Current study & Indian & 6 \\
\hline
\end{tabular}

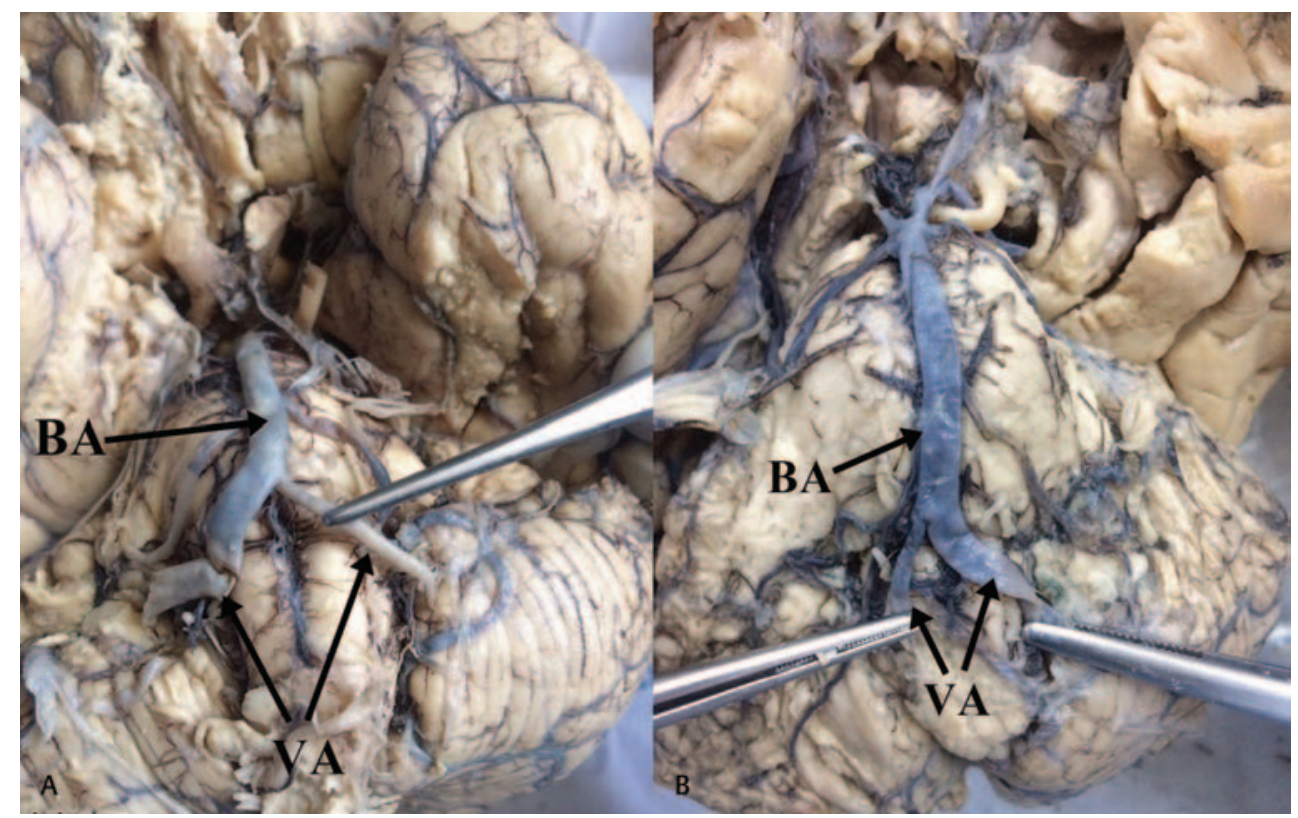

Fig. 5 (A) Mild left vertebral artery hypoplasia. (B) Mild right vertebral artery hypoplasia. Abbreviations: BA, basilar artery. 
Table 6 Frequency of hypoplasia of posterior communicating artery in various populations

\begin{tabular}{|c|c|c|}
\hline References & Population & Prevalence (\%) \\
\hline Chuang et al, $2008^{34}$ & Korean & 19.35 \\
\hline De Silva et al, $2009^{26}$ & Sri Lankan & 51 \\
\hline Dzierżanowski et al, $2014^{38}$ & Polish & 24 \\
\hline $\begin{array}{l}\text { Krabbe-Hartkamp et al, } \\
1998^{36}\end{array}$ & Dutch & 28 \\
\hline Saha et al, $2013^{37}$ & Indian & 23.3 \\
\hline Siddiqi et al, $2013^{28}$ & Pakistani & 39.5 \\
\hline Windle $1888^{35}$ & British & 25 \\
\hline Sinkeet et al, $2010^{39}$ & Kenyan & 25 \\
\hline Iqbal, $2013^{10}$ & Indian & 10 \\
\hline Current study & Kenyan & 40 \\
\hline
\end{tabular}

Table 7 Frequency of vertebral artery hypoplasia in various populations

\begin{tabular}{|l|l|l|}
\hline References & Population & Prevalence of VAH (\%) \\
\hline $\begin{array}{l}\text { Chuang et al, } \\
2008^{34}\end{array}$ & Taiwanese & 10.4 \\
\hline Oder et al, $1998^{42}$ & Austrian & 10 \\
\hline Park et al, 200744 & Korean & 26.5 \\
\hline $\begin{array}{l}\text { Peterson et al, } \\
2010^{45}\end{array}$ & Swizz & 35.8 \\
\hline $\begin{array}{l}\text { Thierfelder et al, } \\
2014^{46}\end{array}$ & American & 15.6 \\
\hline Hu et al, 201347 & Chinese & 10 \\
\hline Current study & Kenyan & 17 \\
\hline
\end{tabular}

Abbreviation: VAH, vertebral artery hypoplasia.

The current study revealed a $17 \%$ prevalence of VAH, higher than those reported for most Caucasian ${ }^{41-47}$ popu-

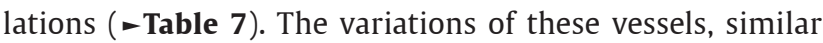
to the above, have been shown to predispose to lacunar infarcts and strokes that have a high prevalence in our setting. This VAH-associated risk is equivalent to that of other conventional risk factors such as hypertension, diabetes, smoking, and dyslipidemia. ${ }^{4}$ Accordingly, nearly $30 \%$ of the Kenyan population may be at risk of posterior circulatory stroke and the other complications. This implies that in patients who present with vertebrobasilar insufficiency, VAH should be considered.

\section{General Remarks}

The frequency of hypoplasia varies between populations. These variations are probably genetically determined, develop early in embryonic life, and persist in postnatal life. ${ }^{11}$ It is also worth noting that in our setting, hypoplasia was predominant in the anterior circulation, specifically in the PCoA.

\section{Conclusion}

The frequency of cerebral arterial hypoplasia is high in the Kenyan population and is more common in the anterior circulation. Due care should be taken during neuroradiological, investigative, and interventional procedures; and patients should be followed up when presenting with cerebrovascular disease.

\section{Funding}

None.

\section{Conflict of Interest \\ None declared.}

\section{Acknowledgments}

The authors are grateful to the staffs working in the Department of Human Anatomy for providing technical assistance and to Antonina Odock for typing the manuscript.

\section{References}

1 Chuang YM, Huang YC, Hu HH, Yang CY. Toward a further elucidation: role of vertebral artery hypoplasia in acute ischemic stroke. Eur Neurol 2006;55(4):193-197

2 Chen YY, Chao AC, Hsu HY, Chung CP, Hu HH. Vertebral artery hypoplasia is associated with a decrease in net vertebral flow volume. Ultrasound Med Biol 2010;36(1):38-43

3 Pascalau R, Padurean VA, Bartos D, Bartos A, Szabo BA. The geometry of the circle of Willis anatomical variants as a potential cerebrovascular risk factor. Turk Neurosurg 2019;29(2):151-158

4 Szarazova AS, Bartels E, Turcani P. Vertebral artery hypoplasia and the posterior circulatory stroke. Perspect Med 2012;1:198-202

5 Rinaldo L, McCutcheon BA, Murphy ME, Bydon M, Rabinstein AA, Lanzino G. Relationship of A1 segment hypoplasia to anterior communicating artery aneurysm morphology and risk factors for aneurysm formation. J Neurosurg 2017;127(1):89-95

6 Chaturvedi S, Lukovits TG, Chen W, Gorelick PB. Ischemia in the territory of a hypoplastic vertebrobasilar system. Neurology 1999;52(5):980-983

7 Vilimas A, Barkauskas E, Vilionskies A, Rudzinskaite J, Moikunate R. Vertebral artery hypoplasia: importance for stroke development, the role of posterior communicating artery, possibility for surgical and conservative treatment. Acta Med Litu 2003;10:110-114

8 Buckenham TM, Wright IA. Ultrasound of the extracranial vertebral artery. Br J Radiol 2004;77(913):15-20

9 Rivera-Rivera LA, Turski P, Johnson KM, et al. 4D flow MRI for intracranial hemodynamics assessment in Alzheimer's disease. J Cereb Blood Flow Metab 2016;36(10):1718-1730

10 Iqbal S. A comprehensive study of the anatomical variations of the circle of Willis in adult human brains. J Clin Diagn Res 2013;7(11):2423-2427

11 Ogeng'o JA, Olabu B, Mburu AN, Sinkeet SR, Ogeng'o MN. Ischemic cortical stroke in a Kenyan referral hospital. J Mol Biomark Diagn 2010;5:238

12 Klimek-Piotrowska W, Rybicka M, Wojnarska A, Wójtowicz A, Koziej M, Hołda MK. A multitude of variations in the configuration of the circle of Willis: an autopsy study. Anat Sci Int 2016;91(4):325-333

13 Tanaka H, Fujita N, Enoki T, et al. Relationship between variations in the circle of Willis and flow rates in internal carotid and basilar arteries determined by means of magnetic resonance imaging with semiautomated lumen segmentation: reference data from 125 healthy volunteers. AJNR Am J Neuroradiol 2006;27(8):1770-1775

14 Zarrinkoob L, Ambarki K, Wåhlin A, Birgander R, Eklund A, Malm J. Blood flow distribution in cerebral arteries. J Cereb Blood Flow Metab 2015;35(4):648-654 
15 Prasad VN, Chhetri PK, Poudel A. normal variants of the circle of Willis in patients undergoing CT angiography. J Coll Med Sci Nepal 2017;13:190-192

16 Valentino L, Ponticiello G, Romano L, Puglisse A. Unilateral congenital hypoplasia of the internal carotid artery in a newborn: a rare case report. J Pediatr Neonatal Individ Med 2015;4:e040121

17 Van Overbeeke JJ, Hillen B, Tulleken CA. A comparative study of the circle of Willis in fetal and adult life. The configuration of the posterior bifurcation of the posterior communicating artery. J Anat 1991;176:45-54

18 Uchino A, Nomiyama K, Takase Y, Kudo S. Anterior cerebral artery variations detected by MR angiography. Neuroradiology 2006;48(9):647-652

19 Chuang YM, Liu CY, Pan PJ, Lin CP. Anterior cerebral artery A1 segment hypoplasia may contribute to A1 hypoplasia syndrome. Eur Neurol 2007;57(4):208-211

20 Dimmick SJ, Faulder KC. Normal variants of the cerebral circulation at multidetector CT angiography. Radiographics 2009;29(4):1027-1043

21 Lakhotia M, Pahadiya HR, Prajapati GR, Choudhary A, Gandhi R, Jangid $\mathrm{H}$. A case of anterior cerebral artery A1 segment hypoplasia syndrome presenting with right lower limb monoplegia, abulia, and urinary incontinence. J Neurosci Rural Pract 2016;7(1):189-191

22 Marshall RS, Lazar RM. Pumps, aqueducts, and drought management: vascular physiology in vascular cognitive impairment. Stroke 2011;42(1):221-226

23 Austin BP, Nair VA, Meier TB, et al. Effects of hypoperfu sion in Alzheimer's disease. J Alzheimers Dis 2011;26 (Suppl 3):123-133

24 Kaspera W, Ładziński P, Larysz P, et al. Morphological, hemodynamic, and clinical independent risk factors for anterior communicating artery aneurysms. Stroke 2014;45(10):2906-2911

25 Makowicz G, Poniatowska R, Lusawa M. Variants of cerebral arteries - anterior circulation. Pol J Radiol 2013;78(3):42-47

26 De Silva KR, Silva R, Gunasekera WS, Jayesekera RW. Prevalence of typical circle of Willis and the variation in the anterior communicating artery: a study of a Sri Lankan population. Ann Indian Acad Neurol 2009;12(3):157-161

27 Nabaweesi-Batuka J, Kitunguu PK, Kiboi JG. Pattern of cerebral aneurysms in a Kenyan population as seen at an urban hospital. World Neurosurg 2016;87:255-265

28 Siddiqi H, Tahir M, Lone KP. Variations in cerebral arterial circle of Willis in adult Pakistani population. J Coll Physicians Surg Pak 2013;23(9):615-619

29 Förster A, Nölte I, Wenz $\mathrm{H}$, et al. Anatomical variations in the posterior part of the circle of Willis and vascular pathology in bilateral thalamic infarction. J Neuroimaging 2014;24(4):325-330

30 Alpers BJ, Berry RG, Paddison RM. Anatomical studies of the circle of Willis in normal brain. AMA Arch Neurol Psychiatry 1959;81(4):409-418
31 Gunnal SA, Farooqui MS, Wabale RN. Study of posterior cerebral artery in human cadaveric brain. Anat Res Int 2015;2015:681903

32 Puchades-Orts A, Nombela-Gomez M, Ortuño-Pacheco G. Variation in form of circle of Willis: some anatomical and embryological considerations. Anat Rec 1976;185(1):119-123

33 Milenković Z, Vucetić R, Puzić M. Asymmetry and anomalies of the circle of Willis in fetal brain. Microsurgical study and functional remarks. Surg Neurol 1985;24(5):563-570

34 Chuang YM, Liu CY, Pan PJ, Lin CP. Posterior communicating artery hypoplasia as a risk factor for acute ischemic stroke in the absence of carotid artery occlusion. J Clin Neurosci 2008;15(12):1376-1381

35 Windle BC. The arteries forming the circle of Willis. J Anat Physiol 1888;22(Pt 2):289-293

36 Krabbe-Hartkamp MJ, van der Grond J, de Leeuw FE, et al. Circle of Willis: morphologic variation on three-dimensional timeof-flight MR angiograms. Radiology 1998;207(1):103-111

37 Saha A, Bhagyalakshmi B, Mandal S, Banopadhyaya M. Variation of posterior communicating artery in human brain: a morphological study. Gomal. J Med Sci 2013;11:41-46

38 Dzierżanowski J, Szarmach A, Słoniewski P, et al. The posterior communicating artery: morphometric study in 3D angio-computed tomography reconstruction. The proof of the mathematical definition of the hypoplasia. Folia Morphol (Warsz) 2014;73(3):286-291

39 Sinkeet S, Ogeng'o J, Saidi H, Awori K. Topography of the posterior communicating artery in a Kenyan population. Ann $\mathrm{Afr}$ Surg 2010;6:37-40

40 Caranci F, Napoli M, Cirillo M, Briganti G, Brunese L, Briganti F. Basilar artery hypoplasia. Neuroradiol J 2012;25(6):739-743

41 Songur A, Gonul Y, Ozen OA, et al. Variations in the intracranial vertebrobasilar system. Surg Radiol Anat 2008;30(3):257-264

42 Oder B, Oder W, Lang W, Marschnigg E, Deecke L. Hypoplasia, stenosis and other alterations of the vertebral artery: does impaired blood rheology manifest a hidden disease? Acta Neurol Scand 1998;97(6):398-403

43 Sabau M, Comanescu A, Popa I. Clinico - Imagistical study of vertebral and basilar artery abnormalities in stroke patients. 21st Meeting of the European Neurological Society; 2011

44 Park JH, Kim JM, Roh JK. Hypoplastic vertebral artery: frequency and associations with ischaemic stroke territory. J Neurol Neurosurg Psychiatry 2007;78(9):954-958

45 Peterson C, Phillips L, Linden A, Hsu W. Vertebral artery hypoplasia: prevalence and reliability of identifying and grading its severity on magnetic resonance imaging scans. J Manipulative Physiol Ther 2010;33(3):207-211

46 Thierfelder KM, Baumann AB, Sommer WH, et al. Vertebral artery hypoplasia: frequency and effect on cerebellar blood flow characteristics. Stroke 2014;45(5):1363-1368

$47 \mathrm{Hu}$ XY, Li ZX, Liu HQ et al. Relationship between vertebral artery hypoplasia and posterior circulation stroke in Chinese patients. Neuroradiology 2013;55(3):291-295 